\title{
Pembuatan Sabun Scrub Kopi sebagai Produk Souvenir Komoditas Lokal di Desa Kaliaren Kabupaten Kuningan
}

\author{
Yeni $^{1}$, Nining $^{1 *}$ \\ ${ }^{1}$ Universitas Muhammadiyah Prof. DR. Hamka, Jakarta \\ *Email koresponden: nining@uhamka.ac.id
}

\begin{abstract}
Abstrak
Peningkatan serapan kopi oleh industri merupakan strategi yang perlu dilakukan dalam memperluas diversifikasi produk kopi. Serapan kopi produksi Indonesia berkisar sekitar 35\% dan sisanya masih diekspor. Desa Kaliaren merupakan salah satu desa di Kecamatan Cilimus Kabupaten Kuningan yang wilayahnya banyak ditanami kopi. Selama ini, penjualaan kopi oleh para petani secara langsung hanya dalam kondisi segar. Oleh karena itu, perlu dilakukannya suatu usaha untuk memvariasikan produk olahan kopi setempat. Salah satu usaha tersebut adalah memberdayakan masyarakat agar mampu secara mandiri memanfaatkan potensi daerahnya yaitu dengan pengetahuan dan keterampilan mengenai wirausaha dan teknologi tepat guna proses pembuatan sabun scrub kopi yang dapat dijadikan produk souvenir komoditas lokal. Dari hasil kegiatan yang telah dilakukan dapat ditarik kesimpulan bahwa: (1) Kegiatan PKM ini dapat meningkatkan motivasi usaha, kesadaran, pengetahuan dan ketrampilan masyarakat melalui penerapan teknologi tepat guna untuk mengolah komoditas lokal menjadi produk sabun scrub; (2) Peserta pelatihan kelompok ibu-ibu PKK dan KWT telah mengikuti serangkaian kegiatan pembuatan sabun scrub selanjutnya perlu dikembangkan kerjasama dengan pihak terkait untuk pengembangan bisnis sabun scrub ke depannya.
\end{abstract}

Kata kunci: sabun scrub kopi, produk souvenir, komoditas lokal

\begin{abstract}
Increased coffee absorption by industry is a strategy that needs to be done in expanding the diversification of coffee products. Indonesian coffee production upsurge is around 35\% and the rest is still exported. Kaliaren Village is one of the villages in Cilimus District of Kuningan Regency which has many coffee areas. So far, direct coffee sales by farmers are only in fresh condition. Therefore, it is necessary to make an effort to vary the local processed coffee products. One such effort is empowering the community to be able to independently exploit the potential of the region that is with knowledge and skills about the entrepreneurship and appropriate technology for the process of making coffee scrub soap that can be used as a local commodity souvenir products. From the results of activities that have been done can be concluded that: (1) PKM activity can improve business motivation, awareness, knowledge and skills of the community through the application of appropriate technology to process local commodities into soap products scrubs; (2) Participants of PKK and KWT women group training have followed a series of scrub making activities so it is necessary to develop cooperation with related parties for the development of soap scrub business in the future.
\end{abstract}

Keywords: coffee scrub soap, souvenir products, local commodities

Format Sitasi: Yeni dan Nining. (2018). Pembuatan sabun scrub kopi sebagai produk souvenir komoditas lokal di Desa Kaliaren Kabupaten Kuningan. Jurnal SOLMA, 7(2), 233-239. Doi: http://dx.doi.org/10.29405/solma.v7i2.1427.

Diterima: 13 Juli 2018 | Revisi: 23 Oktober 2018 | Dipublikasikan: 30 Oktober 2018 


\section{PENDAHULUAN}

Dalam Rapat Pengembangan Nasional Kopi Nasional Tahun 2016 di Lampung, Menteri Perindustrian Saleh Husin menyatakan bahwa diversifikasi produk kopi tidak hanya sebagai minuman tetapi dikembangkan dalam berbagai jenis produk lainnya seperti kosmetik, herbal, farmasi, hingga essen makanan. Maka, mata rantainya makin panjang, beragam dan memberi nilai tambah yang dapat dinikmati petani sampai industri. Industri pengolahan kopi nasional selama ini baru mampu menyerap sekitar 35\% produksi kopi dan sisanya sebesar 65\% masih diekspor. Sedangkan tingkat konsumsi kopi masyarakat Indonesia relatif masih rendah, rata-rata hanya $1,1 \mathrm{~kg}$ perkapita/tahun. Untuk meningkatkan serapan kopi oleh industri, strategi yang perlu dilakukan adalah memperluas ragam pemanfaatan atau diversifikasi produk kopi dari sebelumnya terbatas produk minuman lantas dikembangkan ke industri lainnya (Kemenperin, 2016).

Perkebunan kopi merupakan salah satu komoditas andalan perkebunan Indonesia yang memiliki peranan penting terhadap sektor ekonomi. Indonesia adalah negara penghasil kopi terbesar ketiga di dunia setelah Brasil dan Vietnam dengan produksi pada tahun 2013 sebesar 692 ribu ton atau 8\% dari produksi kopi dunia. Sebagian besar kopi yang diproduksi di Indonesia adalah jenis Robusta (75-80\%). Pada tahun 2013 diperkirakan $60 \%$ bahan baku kopi Indonesia ditujukan untuk pasar ekspor dan sisanya sebesar 40\% atau diolah di dalam negeri (Susanto, 2014).

Desa Kaliaren sebagai salah satu desa di Kecamatan Cilimus Kabupaten Kuningan dengan topografi dataran dan berbukit, luas wilayah 219.023 Ha. Suhu udara rata-rata 18$32^{\circ} \mathrm{C}$, dengan curah hujan rata-rata $2000-2500 \mathrm{~mm} /$ th. Pergantian musim terjadi antara bulan November-Mei adalah musim hujan dan antara bulan Juni-Oktober adalah musim kemarau (BPS Kab. Kuningan, 2015). Produksi tanaman perkebunan kopi di Kecamatan Cilimus mencapai 3,02 ton/tahun.

PKK merupakan sebuah organisasi yang melibatkan partisipasi perempuan dan lakilaki dalam upaya mewujudkan keluarga sejahtera. Kesejahteraan keluarga menjadi tujuan utama PKK. KWT adalah kumpulan istri petani yang membantu kegiatan usaha pertanian, perikanan dan kehutanan dalam meningkatkan pendapatan dan kesejahteraan keluarganya. KWT merupakan suatu wadah para wanita tani agar dapat berhimpun, berusaha dan bekerjasama untuk meningkatkan kesejahteraan keluarga melalui usaha bersama dalam kelompok. 
Menurut Suwitaningrum (2013), permasalahan yang sering dijumpai di lapangan terkait dengan masyarakat desa terutama kaum wanita yaitu adanya keterbatasan dalam permodalan, teknologi, dan oganisasi yang berpengaruh terhadap rendahnya produktivitas usaha dan tanggapan terhadap program pemerintah, sehingga partisipasi kelompok menjadi rendah. Pada level masyarakat, perlu adanya perbaikan akses dan kontrol terhadap beragam sumber daya seperti informasi, penyuluhan, pendidikan, kredit, peluang kerja, dan lainnya. Hal ini sangat mendorong dari berbagai pihak untuk mengadakan pelatihan yang ditujukan untuk pemberdayaan perempuan. Pelatihan yang ada pada masyarakat pedesaan umumnya dimaksudkan untuk mengembangkan sektor pertanian. Pembangunan ekonomi nasional berbasis pertanian dan pedesaan secara langsung maupun tidak langsung akan berdampak pada pengurangan penduduk miskin dan penyelenggaraan kesejahteraan sosial dapat berjalan seperti apa yang sudah dicita-citakan.

Berdasarkan latar belakang tersebut, perlu dilakukan pelatihan yang dapat membantu dalam meningkatkan wawasan dan ketrampilan di kalangan ibu-ibu PKK dan KWT di Desa Kaliaren Kabupaten Kuningan dalam upaya mencapai tujuan bersama melalui kegiatan pengabdian kepada masyarakat oleh dosen Fakultas Farmasi dan Sains UHAMKA. Pelatihan ini memberikan ide diversifikasi produk kopi dalam bentuk sabun scrub yang merupakan salah satu produk farmasi dengan basis komoditas lokal berupa kopi.

\section{MASALAH}

Penjualaan kopi oleh para petani secara langsung memberikan keuntungan yang relatif kecil. Oleh karena itu, perlu dilakukannya suatu usaha untuk meningkatkan perekonomian masyarakat. Salah satu usaha tersebut adalah dengan mengolah kopi menjadi suatu produk yang memiliki nilai jual yang lebih tinggi melalui ekonomi kreatif. Pengembangan ekonomi kreatif dapat dilakukan dengan adanya SDM yang berkualitas dengan daya inovatif dan kreativitas yang tinggi. Namun, di samping kebutuhan akan SDM yang berkualitas, pengembangan ekonomi kreatif juga membutuhkan ruang atau wadah sebagai tempat penggalian ide, berkarya, sekaligus aktualisasi diri dan ide-ide kreatif.

Berdasarkan informasi yang diperoleh secara langsung, belum ada upaya signifikan terkait diversifikasi produk kopi yang dilakukan. Hal tersebut terjadi karena belum ada ide terkait produk olahan lain yang mungkin dapat dibuat dari kopi. Dengan adanya kegiatan pelatihan ini, diharapkan dapat membantu masyarakat kaliaren dalam meningkatkan nilai 
jual kopi melalui produk olahan lainnya sehingga di kemudian hari masyarakat dapat lebih kreatif dan inovatif sehingga perekonomian daerah meningkat.

\section{METODE PELAKSANAAN}

Bahan baku yang digunakan antara lain kopi robusta, minyak kelapa sawit, minyak kelapa, minyak zaitun, $\mathrm{NaOH}$, air, dan pewangi. Alat yang digunakan adalah timbangan, wadah plastik, pengaduk, cetakan sabun, pemotong, dan spatula. Pendekatan yang diterapkan melalui metode participatory approach dengan tahapan sebagai berikut:

a. Pelaksanaan sosialisasi kepada aparat desa terkait program pelatihan untuk memberikan pemahaman dan partisipasi aktif seluruh warga masyarakat.

b. Pengumpulan data dan survei terkait dengan metode pembuatan, jenis sabun, jenis cetakan sabun dan kemasan yang ekonomis agar masyarakat memiliki ketertarikan untuk mengembangkan pembuatan sabun handmade ke depannya.

c. Pelatihan pembuatan produk sabun berbasis komoditas lokal, meliputi:

1. Pelatihan cara membuat sabun handmade, pencetakan, pemotongan sampai ke pengemasan dan pelabelan sabun, selengkapnya di Gambar 1.

2. Pemaparan informasi strategi pengembangan usaha produksi sabun handmade.

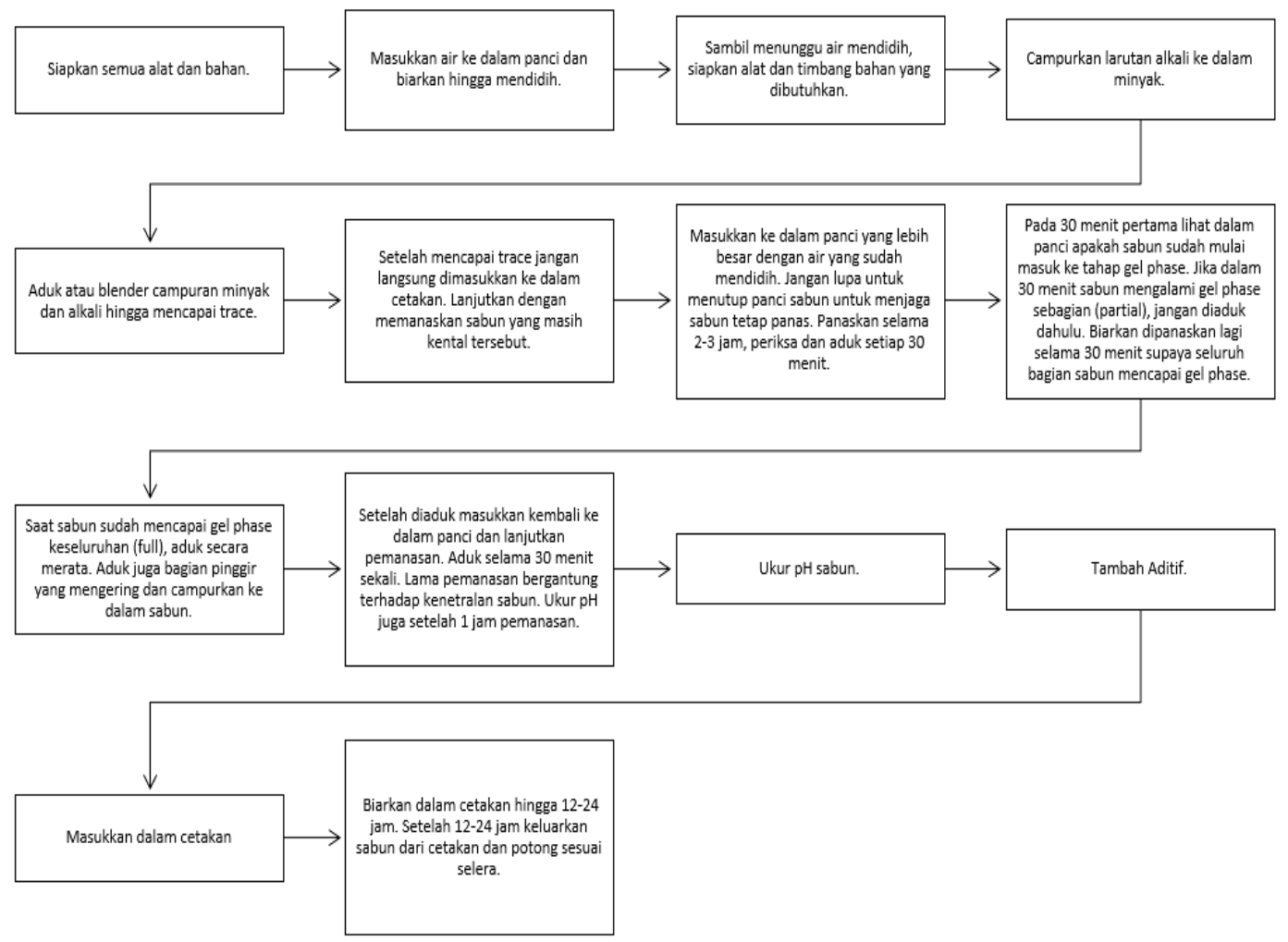

Gambar 1. Diagram Alir Proses Pembuatan Sabun Kopi Handmade 


\section{PEMBAHASAN}

\section{Survei dan Penjajagan Potensi}

Survei dan penjajagan potensi desa dilakukan untuk mendapatkan data mengenai upaya pemanfaatan komoditas lokal berserta permasalahan desa. Selanjutnya dilakukan perancangan dan trial formula sabun scrub kopi di Laboratorium Teknologi Formulasi UHAMKA. Tim pelaksana juga melakukan koordinasi persiapan ATK, bahan habis pakai dan instrumen untuk kegiatan pelatihan sabun diantaranya alat-alat produksi dan pencetak sabun sederhana berupa cetakan alumunium dan cetakan plastik beserta desain kemasan sabun.

\section{Pelatihan Pembuatan Sabun Scrub Kopi}

Setelah dilakukan penjajagan, kegiatan selanjutnya adalah pelatihan pembuatan sabun scrub berbasis komoditas lokal. Desa Kaliaren menggunakan kopi cibeureum sebagai bahan baku sabun. Kegiatan pelatihan dilakukan di Balai Desa Kaliaren pada tanggal 13 Mei 2018. Tingkat partisipasi dari warga masyarakat terlihat dari jumlah peserta yang mengikuti pelatihan sejumlah 28 orang yang berasal dari perwakilan ibu-ibu PKK dan KWT dari masing-masing dusun di Desa Kaliaren.

Sabun merupakan senyawa natrium dengan asam lemak yang digunakan sebagai bahan pembersih tubuh, berbentuk padat, busa dengan atau tanpa zat tambahan lain serta tidak menimbulkan iritasi terhadap kulit (BSN, 1994). Komponen utama pembuatan sabun terdiri dari asam lemak dan garam sodium atau potassium. Asam lemak yang berikatan dengan garam sodium $(\mathrm{NaOH})$ akan menghasilkan sabun padat (hard soap), sedangkan asam lemak yang berikatan dengan garam potassium $(\mathrm{KOH})$ akan menghasilkan sabun cair (soft soap) (Kirk et. al, 1954 dalam Purnamawati, 2006).

Sabun yang berkualitas baik juga dipengaruhi oleh bahan baku yang digunakan. Sabun mandi biasanya dibuat dengan campuran lemak atau minyak. Formulasi sabun scrub yang dibuat di pelatihan ini menggunakan bahan baku minyak zaitun, minyak kelapa dan minyak sawit serta tambahan bahan bubuk kopi produksi lokal. Kopi mengandung asam buah dan asam organik, lemak, alkaloid, mineral, potasium, magnesium, serta besi yang sangat berguna bagi kecantikan kulit. Berfungsi untuk menghaluskan kulit, menetralkan kulit yang teriritasi dan memberi nutrisi, mengangkat sel kulit mati dan memperbaiki jaringan kulit yang rusak serta membantu menghilangkan bau badan. Pembuatan sabun 
padat ini diharapkan mampu menghasilkan produk sabun mandi yang nyaman di kulit, ramah lingkungan dengan harga sebanding dengan khasiat bahan aktif herbalnya.

Sabun dibuat dengan dua cara yaitu proses saponifikasi dan proses netralisasi minyak. Proses saponifikasi minyak akan memperoleh produk sampingan yaitu gliserol, sedangkan proses netralisasi tidak akan memperoleh gliserol (Spitz, 1996). Proses saponifikasi terjadi karena reaksi antara trigliserida dengan alkali, sedangkan proses netralisasi terjadi karena reaksi asal lemak bebas dengan alkali.

Dalam pembuatan produk sabun, terdapat beberapa spesifikasi persyaratan mutu yang harus dipenuhi agar sabun tersebut layak untuk digunakan dan dipasarkan. Spesifikasi persyaratan mutu yang harus dipenuhi pada produk sabun menurut SNI 06-3532-1994 meliputi beberapa parameter sebagai berikut:

Tabel 1. Syarat Mutu Sabun Mandi (SNI 06-3532-1994)

\begin{tabular}{clccc}
\hline No & \multicolumn{1}{c}{ Uraian } & Tipe I & Tipe II & Superfat \\
\hline 1 & Kadar air (\%) & Maks. 15 & Maks. 15 & Maks. 15 \\
2 & Jumlah asam lemak (\%) & $>70$ & $64-70$ & $<70$ \\
3 & Alkali bebas & & & \\
& Dihitung sebagai NaOH (\%) & Maks. 0,1 & Maks. 0,1 & Maks. 0,1 \\
& Dihitung sebagai KOH (\%) & Maks. 0,14 & Maks. 0,14 & Maks. 0,14 \\
4 & Asam lemak bebas (\%) & $<2,5$ & $<2,5$ & $2,5-7,5$ \\
5 & Minyak mineral & Negatif & Negatif & Negatif \\
\hline
\end{tabular}

(Sumber : BSN, 1994)

Sabun tipe I merupakan sabun yang terbaik karena mengandung jumlah asam lemak yang tinggi (lebih dari 70\%) dengan asam lemak bebas yang rendah yaitu kurang dari $2,5 \%$. Sabun tipe I, II, dan superfat merupakan sabun yang dapat dipasarkan di masyarakat karena aman untuk digunakan. Sabun tipe II lebih baik dari superfat karena kandungan asam lemak bebasnya kurang dari 2,5\%.

\section{Indikator Keberhasilan Pelatihan}

Evaluasi kegiatan pelatihan di Desa Kaliaren dilakukan dengan melihat peran aktif peserta selama proses pelatihan dari awal sampai akhir kegiatan. Kegiatan dimulai dengan melemparkan beberapa pertanyaan terkait produk olahan kopi dan serba-serbi pembuatan sabun. Setelah pemaparan materi selesai, kegiatan dilanjutkan dengan workshop pembuatan sabun secara langsung dalam tiga kelompok peserta. Diakhir pelatihan, banyak peserta menanyakan berbagai hal terkait teknis produksi skala rumah tangga. Sehingga dapat dikatakan bahwa tingkat penerimaan dan antusiasme peserta terhadap materi pelatihan sangatlah tinggi. Peserta juga menyampaikan beberapa pesan, saran dan kesan 
kepada tim, sehingga dapat menjadi bahan evaluasi pelaksanaan kegiatan pelatihan. Adapun kriteria dan indikator keberhasilan pelatihan ini terlihat pada Tabel. 2.

Tabel 2. Kriteria dan Indikator Keberhasilan Pelatihan

\begin{tabular}{|c|c|c|}
\hline No. & Indikator & Kriteria \\
\hline 1. & $\begin{array}{l}\text { Pengetahuan mengenai pemanfaatan potensi } \\
\text { lokal pertanian dan perkebunan menjadi } \\
\text { produk sabun handmade }\end{array}$ & $\begin{array}{l}\text { Peserta aktif mengemukakan saran } \\
\text { pertanyaan selama pelatihan }\end{array}$ \\
\hline 2. & $\begin{array}{l}\text { Minat dan ketrampilan masyarakat dalam } \\
\text { proses pembuatan sabun handmade mulai } \\
\text { dari persiapan bahan, pencetakan, } \\
\text { pengemasan hingga ke pemasarannya }\end{array}$ & $\begin{array}{l}\text { Peserta sangat antusias dan bekerjasama } \\
\text { dengan instruktur pelatihan mulai dari } \\
\text { kegiatan pencampuran, pencetakan, dan } \\
\text { pengemasan pelabelan. }\end{array}$ \\
\hline 3. & Kesesuaian materi pelatihan & $\begin{array}{l}\text { Materi penyuluhan sudah sesuai dengan } \\
\text { kebutuhan masyarakat untuk meningkatkan } \\
\text { nilai tambah komoditas lokalnya }\end{array}$ \\
\hline 4. & Tingkat partisipasi peserta & $\begin{array}{l}\text { Jumlah partisipasi warga sudah melebihi } \\
\text { target kegiatan yang sebelumnya hanya } 10 \\
\text { orang dan berasal dri perwakilan tiap dusun. }\end{array}$ \\
\hline
\end{tabular}

Adapun prototipe produk sabun scrub kopi yang dihasilkan setelah pelatihan adalah dibawah ini:

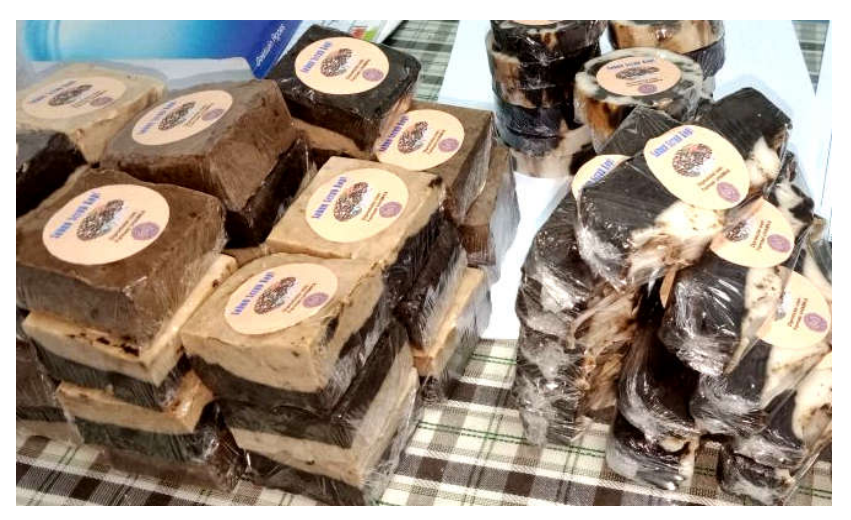

Gambar 2. Prototipe Produk Sabun Scrub Kopi

\section{KESIMPULAN}

Kegiatan pelatihan ini dapat meningkatkan motivasi usaha, kesadaran, pengetahuan dan ketrampilan masyarakat melalui penerapan teknologi tepat guna untuk mengolah komoditas lokal menjadi produk sabun scrub. Peserta pelatihan kelompok ibu-ibu PKK dan KWT telah mengikuti serangkaian kegiatan pembuatan sabun scrub selanjutnya perlu dikembangkan kerjasama dengan pihak terkait untuk pengembangan bisnis sabun scrub ke depannya dalam upaya mempromosikan sabun scrub sebagai souvenir non-pangan dari kabupaten Kuningan. 


\section{UCAPAN TERIMA KASIH}

Terima kasih kami ucapkan kepada Lembaga Pengembangan dan Pemberdayaan Masyarakat (LPPM) Universitas Muhammadiyah Prof. DR. Hamka yang telah mendukung dan memberikan dana sehingga dapat terlaksananya kegiatan ini.

\section{DAFTAR PUSTAKA}

Badan Standarisasi Nasional., 1994. Standar Mutu Sabun Mandi. SNI 06-3532-1994. Dewan Standardisasi Nasional. Jakarta.

BPS Kab. Kuningan. 2015. Kabupaten Kuningan dalam Angka (Kuningan Regency in figure). Katalog BPS: 1102001.3208.

Kemenperin. 2016. Siaran Pers: Menperin Pacu Diversifikasi Kopi ke Non-Pangan. http://kemenperin.go.id/artikel/14395/Menperin-Pacu-Diversifikasi-Kopi-ke-NonPangan.

Purnamawati, Debbi. 2006. Kajian Pengaruh Konsentrasi Sukrosa dan Asam Sitrat terhadap Mutu Sabun Transparan. Skripsi. Fakultas Teknologi Pertanian, Institut Pertanian Bogor. Bogor

Spitz, L. 1996. Soap and Detergent, A Theoretical and Practical Review. Illinois: AOCS Press.

Susanto, Panggah. 2014. Kebijakan Pemerintah Dalam Mendorong Industrialisasi Kopi, Kakao, Dan Teh Di Indonesia. Roundtable Bidang Agribisnis dan Pangan KADIN Indonesia. Jakarta.

Suwitaningrum, NY. 2013. Kelembagaan Kelompok Wanita Tani (KWT) Pengolah Hasil Pertanian (Studi pada KWT di Kota Salatiga). Tesis. Prodi Magister Studi Pembangunan. Universitas Kristen Satya Wacana. Salatiga.

(C) 2018 Oleh authors. Lisensi Jurnal Solma, LPPM-UHAMKA, Jakarta. Artikel ini bersifat open access yang didistribusikan di bawah syarat dan ketentuan Creative Commons Attribution (CC BY) license (http://creativecommons.org/licenses/by/4.0/). 